\title{
AUTOVALORIZAÇÃO E DESCORTESIA NO DEBATE ELEITORAL: UMA ANÁLISE DO DEBATE POLÍTICO TELEVISIVO DE 1989
}

\author{
Ronaldo de Oliveira BATISTA ${ }^{1}$ \\ Mariana Santos de ANDRADE ${ }^{2}$
}

\begin{abstract}
Resumo: Este artigo propõe analisar manifestações descorteses no debate presidencial televisivo de 1989, que visava à eleição do presidente do Brasil em primeiro turno. No exame do material, busca-se depreender e analisar estratégias comunicativas provenientes do uso de atos descorteses. Para tanto, serão adotados como base teórica principal os pressupostos sobre as atividades sociais de cortesia e de descortesia defendidos por Bravo (1999, 2003, 2004a, 2004b), Blas Arroyo (2001, 2010) e Silva (2013), valendo-se de uma análise documental, na qual trechos de vídeos televisivos dos debates constituem o corpus. Por fim, deve-se levar em consideração que se tem no gênero debate político uma interação conflituosa, na qual o objetivo costuma ser denegrir a imagem do outro e enaltecer a própria, tendo em mira a conquista de votos, o que pode transformar a descortesia em norma.
\end{abstract}

Palavras-chave: Descortesia. Debate Político. Análise da Conversação. Pragmática.

\section{Considerações iniciais}

Revisões da teoria da polidez de Brown e Levinson (1978, 1987), desde o estabelecimento dessas primeiras reflexões sobre cortesia nas práticas comunicativas, ampliaram o escopo dos estudos acerca dos modos de interação verbal e gerenciamento das imagens e das estratégias linguísticas. Em meio a uma série de debates sobre a pertinência ou não das propostas em Politeness: Some Universals in Language Use

\footnotetext{
${ }^{1}$ UPM - Universidade Presbiteriana Mackenzie - Centro de Comunicação e Letras. São Paulo - São Paulo - Brasil. 01241-001 - robatista@mackenzie.br

${ }^{2}$ UPM - Universidade Presbiteriana Mackenzie - Centro de Comunicação e Letras. São Paulo - São Paulo

- Brasil. 01241-001 - mariana_s.a@hotmail.com
}

http://dx.doi.org/10.21165/gel.v14i1.1481 
(BROWN; LEVINSON, 1987), algumas considerações gerais sobre o uso da linguagem, a cortesia e a descortesia (ou polidez e impolidez, considerando os termos como equivalentes) podem ser estabelecidas: a) mais do que seleção e uso de recursos linguísticos, a cortesia é elemento constituinte da interação verbal; b) cortesia é fenômeno linguístico e social; c) estratégias de uso da língua com vistas a observar cortesia, a dinâmica discursiva e a negociação de papéis dos interlocutores estão relacionadas a variáveis de natureza social e histórica; d) cortesia e descortesia não são fenômenos unilaterais ou estanques, mas complexos em sua configuração, resultantes que são de uma conjuntura social-discursiva dinâmica, diante das possibilidades de interação verbal e contextos de troca linguística ${ }^{3}$.

Inserindo-se nessa perspectiva de estudos pragmáticos, este artigo propõe analisar manifestações descorteses no debate presidencial televisivo de 1989, que visava à eleição do presidente do Brasil em primeiro turno. Para tanto, considera-se que "a descortesia merece uma atenção especial no macro diálogo político, porque tem um valor ideológico e pode ser usada com diferentes 'funções estratégicas' na interação política ${ }^{4 \text { ” }}$ (BOLÍVAR, 2003, p. 213). Essa atividade social - a descortesia -, mesmo que possa ser atenuada, é utilizada em um contexto de debate político como ameaça proposital à imagem de candidatos à eleição, de maneira a enaltecer a imagem de determinados enunciadores no processo comunicativo. Dessa forma, os atos descorteses podem tornarse a regra em determinados tipos de interações polêmicas (as que buscam denegrir o coenunciador por meio da palavra), como ocorre no debate eleitoral face a face:

Em determinados tipos de discurso, no entanto, o conflito, a crítica e o ataque pessoal desempenham papel importante para o sucesso da interação. Tais atos são denominados de atos descorteses (grifo do autor), pois a intenção não é evitar a ameaça potencial de certos atos, pelo contrário, a intenção é denegrir, desvalorizar, ofender o interlocutor. Nesses casos, a descortesia (grifo do autor) torna-se a regra, pois se trata de uma estratégia para se conseguir um determinado benefício. (SILVA, 2013, p. 102)

\footnotetext{
${ }^{3}$ Esta análise não faz uso do conceito de "ato ameaçador da face", tal como elaborado por Brown e Levinson. O referencial teórico aqui utilizado é aquele que se configura como uma revisão, entre outros, por Blas Arroyo, Bolívar e Culpeper, das ideias de polidez defendidas por Brown e Levinson no clássico Politeness.

${ }^{4}$ Tradução nossa do original: "La descortesía merece una atención especial en el macro diálogo político porque tiene un valor ideológico y puede usarse con diferentes 'funciones estratégicas' en la interación política” (BOLÍVAR, 2003, p. 213).
} 
O corpus deste artigo é parte da interação entre os candidatos Mário Covas, do PSBD (Partido da Social Democracia Brasileira), Leonel Brizola, do PDT (Partido Democrático Trabalhista), Paulo Maluf, do PDS (Partido Democrático Social), Afonso Camargo, do PTB (Partido Trabalhista Brasileiro), Aureliano Chaves, do PFL (Partido da Frente Liberal), Luiz Inácio Lula da Silva, do PT (Partido dos Trabalhadores), Ronaldo Caiado, do PSD (Partido Social Democrático), Guilherme Afif Domingos, do PL (Partido Liberal), Roberto Freire, do PCB (Partido Comunista Brasileiro). Esse debate foi mediado pela jornalista Marília Gabriela e transmitido pela rede Bandeirantes no dia 17 de julho de 1989, época do primeiro pleito direto para Presidente da República depois da ditadura ${ }^{5}$.

O método de análise utilizado consiste em uma análise documental, considerando os vídeos selecionados como o documento a partir do qual se identificaram os trechos pertinentes à análise aqui proposta. Dessa fonte original, tendo em vista as informações que o documento contém, estratégias pragmáticas utilizadas pelos falantes foram definidas para que se pudesse alcançar a perspectiva interpretativa pretendida, que procura evidenciar a presença dessas estratégias em relação à descortesia no âmbito do discurso político. Sendo assim, o tratamento do corpus obedeceu aos seguintes procedimentos: a) análise do conteúdo do material; b) identificação de trechos que evidenciam o uso das estratégias pragmáticas que buscamos analisar; c) transcrição dos trechos selecionados; d) análise dos trechos selecionados; e) síntese interpretativa dos resultados alcançados na análise.

\section{O debate político}

Evento que se tornou tradição no regime democrático, o debate eleitoral foi idealizado para que os políticos tenham a chance de expor suas ideias e propostas de governo, auxiliando os eleitores na escolha do candidato mais adequado para governar. Assim, trata-se de um tipo de interação verbal e prática discursiva de relevância no espaço social, pois faz com que seus interlocutores e espectadores ampliem o conhecimento acerca dos projetos políticos dos participantes.

Em relação ao meio televisivo, Weber (2000, p. 144) inclusive afirma que

\footnotetext{
5 MULLER, Luciana. Legislação e Debate. Disponível em: < http://www.trerj.gov.br/eje/gecoi_arquivos/arq_050860.pdf> . Acesso em: 08 nov. 2015.
} 
[a] televisão está para os debates políticos como o voto para as democracias. [...] A instituição televisiva é obrigada a se oferecer como espaço de mediação para a disputa democrática e investir para que isso aconteça”. São circunstâncias que beneficiam a dimensão pública da comunicação, pois de algum modo permitem aos candidatos um confronto onde sua individualidade se sobrepõe à campanha. Permitem, também, que o receptor-eleitor seja testemunha e haja repercussão e outros debates, para além da tela. É o momento em que a dramaturgia explícita na campanha e no marketing eleitoral pretende ser resignificada para ser compreendida como um momento próximo à verdade.

O debate político veiculado na televisão organiza-se de forma específica e tem suas próprias características. Trata-se, primeiramente, de um processo comunicativo no qual se tem ao menos dois participantes que apresentam ideias distintas. A partir disso, é proposta uma interação entre eles para que suas opiniões sejam discutidas.

Apesar de regras particulares, os debates políticos televisivos costumam seguir um mesmo modelo, no qual o início da discussão é declarado por um mediador, que explica as normas e apresenta os candidatos. São feitas perguntas, respostas, réplicas e tréplicas, sendo que alguns questionamentos já são determinados previamente e outros são de tema livre.

A declaração de início e término do debate político, o controle e distribuição de turnos e o tempo que cada participante tem para expor sua fala são de responsabilidade do mediador. Em tese, as normas são rígidas, o que confere igualdade aos candidatos e imparcialidade ao mediador e à emissora na qual a discussão é veiculada.

A interação é construída, então, por um mediador, pelos debatedores, ou seja, políticos representando seus partidos, e pelo público eleitor. Embora os eleitores não participem diretamente, na maioria dos casos, a discussão é formulada de maneira a atender suas expectativas, ajudando-os no exercício da escolha de um representante. A forma com a qual os candidatos se comportam, inclusive, deve levar em consideração o propósito de manter a imagem que eles construíram diante desse público.

Nesta análise, serão estudadas algumas interações entre candidatos, considerando os propósitos deste texto. Tendo em vista que os interactantes são adversários, considerase o debate como uma discussão repleta de controvérsias, na qual são apresentadas opiniões sobre temas e questões que, em geral, interessam aos eleitores. 


\section{Imagens na interação verbal}

O conceito de imagem foi inicialmente proposto por Goffman (1967), que apresentava uma preocupação em analisar como funcionavam os processos interacionais. Em seus estudos (1967, p. 77), afirma que esse conceito representa o "valor social positivo que uma pessoa reclama para si mesma através daquilo que os outros presumem ser a linha por ela tomada durante um contato específico”.

Brown e Levinson (1987, p. 61), embora tenham sido, como dissemos, alvo de revisões ${ }^{6}$, propuseram um aperfeiçoamento da noção de imagem que teve grande repercussão nos estudos sobre cortesia, defendendo que essa pode ser negativa ou positiva. De acordo com esse modelo, a primeira está relacionada à intenção de manter um território próprio e pessoal, que possui liberdade e não sofre imposições, enquanto a segunda diz respeito à autoimagem reivindicada pelos interactantes, o que envolve desejos de aprovação e de apreciação.

Em meio às revisões dessa proposta inicial, Bravo $(1999,2003)$ sugere que existem algumas necessidades humanas vinculadas à noção de imagem: a autonomia, que está relacionada à maneira com a qual o indivíduo percebe a si mesmo e como os demais o percebem como alguém com um espaço próprio dentro de determinado grupo; e a afiliação, que é tudo aquilo que colabora para que o indivíduo se identifique com um grupo, inclusive o que faz com que as outras pessoas o percebam como parte desse grupo. A linguista diz que, por se tratar de princípios humanos, supostamente seriam universais, ao contrário da divisão imagem positiva e negativa. Além disso, o que diferencia a proposta de Bravo (1999) da noção elaborada por Brown e Levinson (1987) é que esses conceitos não devem ser vistos como categorias de diferenciação, mas como categorias inicialmente vazias, as quais devem ser preenchidas no processo de análise, de acordo com contextos socioculturais específicos ${ }^{7}$.

\footnotetext{
${ }^{6}$ De maneira geral, revisões do modelo de Brown e Levinson (1987) propõem suas críticas baseadas nos seguintes pontos: a) o caráter etnocentrista da teoria; b) uma alegada inadequação quanto à universalidade da cortesia; c) ausência de análises da descortesia (BRAVO, 1999, 2003, 2004a, 2004b; CULPEPER, 1996; HERNÁNDEZ FLORES, 2004).

${ }^{7}$ Essas nomenclaturas foram adotadas neste estudo, porque são categorias que devem ser preenchidas no momento da análise, de acordo com o contexto sociocultural no qual a interação se insere, o que facilita a aplicação desses conceitos em diferentes culturas e situações. Além disso, ao adotar essas noções, fica claro que não se faz juízo de valor, confusão possível ao utilizar as nomenclaturas imagem positiva e negativa, propostas por Brown e Levinson (1987).
} 
Uma das mais conhecidas críticas ao modelo de Brown e Levinson é a de Culpeper (1996), que acredita haver problemas na desconsideração de fenômenos de descortesia. Assim, o estudioso propôs que o coenunciador pode responder ou não ao ato descortês. Em caso de resposta, ele pode contrariar ou aceitar o ato. Caso escolha contrariar, pode fazê-lo de maneira ofensiva (o coenunciador, com a imagem ameaçada, ataca aquele que lhe proferiu um ato descortês) ou defensiva (o coenunciador procura defender a própria imagem por meio de recursos diversos, como ignorar o ato descortês ou responsabilizar outros). Caso escolha aceitar o ato de descortesia, mediante um pedido de desculpas, o coenunciador assume a responsabilidade de ter sido vítima de um ato descortês.

Sobre a cortesia, Hernández Flores (2004) aponta, ainda, para o fato de que essa atividade social não é utilizada somente para mitigar ameaças, como defendido por Brown e Levinson (1987). Esse fenômeno é também usado para realçar as imagens do enunciador e do coenunciador, considerando esse como um dos motivos que fazem com que um falante seja cortês. Ou seja, a cortesia traz benefício mútuo às imagens, sendo que serve tanto para fazer com que o ouvinte se sinta bem e que sua imagem seja valorizada, quanto para beneficiar o próprio falante, que legitima o ethos de educado e simpático, características apreciadas no convívio em sociedade. Dessa forma, a cortesia é um tipo de atividade de imagem que pode ser compreendida como

Uma estratégia para se dar bem com o outro, seja como um objetivo primordial (por exemplo uma saudação, um agradecimento, um elogio), seja para atenuar algo que possa levar o locutor a parecer rude e descortês frente a seus interlocutores (uma crítica imprópria) ou de ser particularmente amável com o objetivo de obter benefícios extrainterlocutivos $^{8}$. (BRAVO, 2003, p. 101-102, grifo da autora)

No entanto, há determinados tipos de interação conflituosos por natureza, o que faz com que a descortesia passe a ser a norma. Ao contrário da cortesia, que visa manter a harmonia por meio da preservação ou enaltecimento das imagens, a descortesia pode ser vista como um fenômeno que objetiva denegrir a imagem do coenunciador. Assim, a noção de imagem está intrinsecamente conectada também às manifestações de

\footnotetext{
${ }^{8}$ Tradução nossa do original: "una estratégia para quedar bien con el otro ya sea manifestada como un objetivo primordial (por ejemplo un saludo, un agradecimiento, un halago) ya sea que se trate de una atenuación de algo que puede hacer quedar al hablante como rudo y descortés frente a sus interlocutores (una crítica inapropiada) o de ser particularmente amable con el objetivo de obtener beneficios extrainterlocutivos” (BRAVO, 2003, p. 101-102, grifo da autora).
} 
descortesia, especialmente aquelas que ocorrem no âmbito do discurso político. Dessa forma, ser descortês viola as normas interacionais cotidianas; no entanto, considera-se que a descortesia pode ser utilizada como estratégia em determinados discursos. Tendo apontado essas questões, adota-se, ainda, a noção de que

[u]m dos aspectos mais relevantes no estudo desse extremo menos harmônico e eventualmente sem adornos, das relações interpessoais é a constatação de que tanto o caráter como o grau que alcançam os comportamentos descorteses são intimamente relacionados com os contextos que se desenvolvem, sejam esses de caráter individual, cultural ou institucional. A propósito desses últimos, por exemplo, temse chamado a atenção sobre a existência de diversos tipos de discurso em que o comportamento interacional esperável por parte dos participantes é, justamente, da agressividade verbal e da descortesia, como ocorre com os debates políticos ${ }^{9}$ (BLAS ARROYO, 2010, p. 184).

Como mencionado, deve-se considerar que nem toda interação busca harmonia, uma vez que há aquelas de cunho polêmico. Nesses processos comunicacionais, o que se busca é a valorização da própria imagem, ao mesmo tempo em que se menospreza a imagem do coenunciador, como acontece nos debates políticos, tendo em vista que nesse tipo de evento

[...] mais importante do que manter o equilíbrio das relações sociais, é colocar em risco a imagem do adversário político, com a finalidade de conquistar votos. Dessa forma, os participantes esforçam-se para construir uma imagem que lhes seja favorável e, ao mesmo tempo, buscam desconstruir a imagem pública do adversário político. (SILVA, 2013, p. 93)

\footnotetext{
${ }^{9}$ Tradução nossa do original: "Uno de los aspectos más relevantes en el estudio de este extremo menos armónico, y eventualmente descarnado, de las relaciones interpersonales es la constatación de que tanto el caráter como el grado que alcanzan los comportamientos descorteses se hallan íntimamente relacionados con los contextos en que se desenvuelven, sean estos de caráter individual, cultural o institucional. A propósito de estos últimos, por ejemplo, se ha llamado la atención acerca de diversos tipos de discurso en los que el comportamiento interaccional esperable por parte de los participantes es, justamente, el de la agresividad verbal y la descortesía, como ocurre con los debate políticos" (BLAS ARROYO, 2010, p. 184).
} 


\section{Estratégias de descortesia}

Nesta análise, foram adotados como principal base teórica os trabalhos de Blas Arroyo (2001) e Silva (2013), que sugeriram algumas estratégias de descortesia para serem investigadas. Tais estratégias podem ser utilizadas por adversários em um debate político, objetivando fragilizar a imagem do outro (o interlocutor) ao mesmo tempo em que se enaltece a imagem do enunciador. Para identificá-las no corpus, foram selecionados alguns fragmentos do debate nos quais essas táticas se manifestam de maneira mais evidente.

\section{a) Autovalorização}

A autovalorização ocorre quando os candidatos se autopromovem, desvalorizando seus oponentes. Trata-se da "exaltação das próprias qualidades em detrimento das dificuldades e deficiências do outro" (SILVA, 2013, p. 105). A função dessa estratégia é levar o público eleitor a olhar de maneira crítica para o adversário, atentando-se às qualidades do enunciador, como se observa no exemplo a seguir:

Paulo Maluf: [...] você que ganha muito e não trabalha nada, não vote no Maluf, porque o Maluf eleito vai te demitir, você que é Marajá, também não vote no Maluf, você [eleitor] tem uma porção de gente para votar, você que é a favor da mordomia, não vote no Maluf. ${ }^{10}$

No trecho apontado, Paulo Maluf procura promover sua imagem afiliativa, apresentando-se como parte de um grupo que age contra a corrupção e a favor do trabalho. Afirma, ainda, que quem não trabalha "tem uma porção de gente para votar", ou seja, trata-se de um ato de fala em que a real intenção não é apontar as opções de voto dos eleitores, mas sim acusar seus oponentes de apoiar aqueles que são pagos para não realizar atividade alguma, ameaçando a imagem dos demais candidatos, ao mesmo tempo em que se mostra contra essa iniciativa.

\footnotetext{
${ }^{10}$ Os fragmentos do corpus de análise serão citados no texto com destaque em itálico, espaço 1,5 e adentramento de 1,25 cm, para que se possa diferenciá-los de textos teóricos citados.
} 
Além disso, o candidato Maluf repete a todo momento seu nome, objetivando enfatizar uma nova imagem que buscava criar para si naquele momento, já que havia sido derrotado em três outras eleições, em 1985, 1986 e 1989.

A partir do apontado, pode-se inferir que o político decidiu usar a estratégia de descortesia de autovalorização para colaborar no processo de restauração de sua imagem, que estava abalada diante do público eleitor. Dessa forma, ser descortês no contexto do discurso político pode ser compreendido como uma tentativa de recuperar a própria imagem, por meio da ameaça à imagem dos adversários, apontando fragilidades destes e, em consequência, se autopromovendo.

Pode-se compreender que, nas estratégias de autovalorização, o candidato também procura estabelecer uma imagem de autonomia, pois quer se apresentar como diferente dos demais políticos, construindo-se como a melhor opção de voto.

Dessa forma, Paulo Maluf fez uso da estratégia de autovalorização também na tentativa de legitimar o ethos de político competente e honesto, que visava construir por meio de suas práticas discursivas, buscando persuadir o público eleitor e conquistar votos.

b) Desqualificação do outro

Essa estratégia ocorre quando os adversários buscam apontar fragilidades no outro, ameaçando imagens pelo destaque dado a características negativas em um político, como a incompetência, o que ocorre na interação a seguir entre Ronaldo Caiado e Afif Domingos:

Ronaldo Caiado: Eu tenho certas preocupações na antecipação para primeiro de janeiro. Sabe por quê? Porque, em primeiro lugar, o presidente eleito, ele terá que ter um perfil, uma radiografia do país. Ele não pode já chegar sem saber sequer o sintoma do paciente e já apresentar o tratamento. Então eu acho que esse período, Afif, eu acho fundamental para podermos fazer uma auditoria, um levantamento. Sabermos diagnosticar corretamente quais são os pontos que nós devemos atacar e como nós devemos atacar para não desestabilizar esse governo frágil e essa máquina que está aí hoje, governando esse país. Por isso eu gostaria de refletir sobre esse ponto, mas, primeiro lugar, eu acho que devemos manter as datas já previamente fixadas. 
Nesse primeiro momento, Ronaldo Caiado responde à indagação de Afif Domingos a respeito de adiantar a posse presidencial. Em sua fala, o candidato acusa indiretamente seu adversário de não estar suficientemente preparado para assumir a presidência, uma vez que "não pode já chegar sem saber sequer o sintoma do paciente e já apresentar o tratamento”, ou seja, para fazer um trabalho competente, deve haver reflexão e tempo. O político inclusive coloca como um risco a proposta de Afif Domingos de adiantar as datas, dizendo que o presidente eleito deve tomar cuidado "para não desestabilizar esse governo frágil e essa máquina que está aí hoje”. Esse enunciado ameaça a imagem do oponente, uma vez que lhe é atribuída a característica de irresponsável.

Ronaldo Caiado usa o pronome "nós” inclusivo para defender que todos os presidenciáveis deveriam ter a preocupação de analisar o país antes de assumir a presidência, consciência que ele julga ter e que usa como argumento para prejudicar Afif Domingos. Ao final de sua fala, passa a usar o pronome "eu” para enfatizar sua imagem e autopromover-se, afirmando a importância da reflexão. Termina, ainda, dizendo "eu acho”, o que ameniza a intenção real de discordância do seu enunciado, de maneira a não prejudicar sua própria imagem. Dessa forma, apresentar a proposta de Afif Domingos como algo impensado e arriscado para o país é afirmar sua incompetência, ameaçando uma imagem diante do público eleitor.

Além disso, o candidato também é descortês ao escolher realizar a pergunta retórica “Sabe por quê?”, uma vez que esse tipo de questionamento não é cooperativo, considerando que se trata de uma indagação que, no caso, tem a resposta dada pelo próprio enunciador. Pode-se dizer ainda que, nessa resposta formulada pelo indagador, tem-se uma tomada de posição contrária à opinião de seu interlocutor, enfatizando o conflito no uso de tal mecanismo.

Na continuação do diálogo, Afif Domingos responde:

Afif Domingos: É. Eu volto a insistir porque eu acho que quem se predispõe a se candidatar à presidência da república tem que ter em mente um quadro muito claro de diagnóstico da situação e, acima de tudo, essa campanha é para se apresentar projetos de governo. Projetos de governo já em debate com a sociedade e aqui nós começamos hoje este grande debate, colocando claramente 
os pontos de vista e, acima de tudo, já ir preparando uma equipe para assumir o governo imediatamente. Nós já estamos preparados para isso, por isso que fomos um dos primeiros a apresentar um projeto completo para a discussão da sociedade, registamos no Congresso Nacional e acho que deve existir uma sabatina no Congresso Nacional com todos os candidatos, mostrando a que vieram. Exatamente para que haja uma espécie de serviço de proteção ao eleitor, para que nós não corramos o risco de só ter caixinha bonitinha sem nada dentro, ou seja, apresentar a embalagem sem apresentar a essência do produto. Por isso eu acredito que nós precisamos estar prontos, qualquer um de nós, para assumir o país em qualquer momento. Eu estou pronto.

Segundo Culpeper (1996), diante de uma ameaça à imagem, o interlocutor pode responder à crítica ou ficar em silêncio. O que costuma acontecer nos debates políticos é a resposta à crítica composta por tentativa de preservar, restaurar ou enaltecer a própria imagem e/ou denegrir a imagem dos adversários no processo. No trecho em questão, o candidato Afif Domingos responde à crítica de Ronaldo Caiado, acusando-o de incompetência ao dizer que ele não tem projetos de governo, preparo essencial, de acordo com ele, para quem quer chegar à presidência. Afif defende, inclusive, que esses projetos deveriam ser uma condição básica para quem se candidata a tal cargo político, o que denigre a imagem de Ronaldo Caiado, pois ele ainda não havia apresentado seus projetos, ou seja, faltou-lhe competência para cumprir uma função essencial.

Ao iniciar sua fala, Afif não parece discordar de seu adversário, “É. Volto a insistir [...]”, e retoma o tema abordado. Trata-se de uma tentativa do candidato de manter a educação, acusando o outro com sutileza para não prejudicar sua própria imagem. Com esse objetivo, o político iniciou sua fala com a expressão de assentimento "é”. A sutileza em sua estratégia de descortesia reside, ainda, no uso do pronome "nós" inclusivo em "para que nós [políticos em geral] não corramos o risco de só ter caixinha bonitinha sem nada dentro, ou seja, apresentar a embalagem sem apresentar a essência do produto”. Esse “nós” representa todos os políticos, mas o candidato o usa de tal maneira que o possibilita apontar uma fragilidade em seu adversário.

Em outro momento, o político faz uso do pronome "nós" exclusivo para autopromover-se, dizendo que “nós [seu partido] já estamos preparados para isso”. 
Enfatiza, ainda, sua competência, ao final de sua fala: “eu estou pronto”, auto afirmando a própria imagem por meio do pronome “eu”. Trata-se, ainda, de um ato de fala assertivo, que pode conduzir a outro ato implícito: a afirmação de que os demais candidatos não tiveram a mesma competência que seu partido; o que ameaça a imagem dos oponentes, porque o preparo e a competência são características esperadas pelo público eleitor em seus governantes.

Como no caso da estratégia de autovalorização, essas escolhas linguísticas foram feitas pelos candidatos Ronaldo Caiado e Afif Domingos em uma tentativa de legitimar os ethé que eles procuram estabelecer: o primeiro buscou enaltecer a imagem do candidato cuidadoso e responsável, ao passo que o segundo quis se mostrar competente. Além disso, ambos procuraram, também, valorizar suas próprias imagens, apresentando propósitos persuasivos, de maneira a denegrir a imagem do adversário.

c) Formulação de contrastes desvantajosos

Essa estratégia ocorre quando são feitas comparações que objetivam denegrir a imagem dos demais candidatos, ao mesmo tempo em que melhoram a imagem de quem a utiliza, como se pode observar no exemplo a seguir:

Afonso Camargo: [...] E exatamente nessa expectativa que eu achava que essa... o nosso encontro seria um encontro bastante afável, bastante respeitoso, baixou o nível em alguns momentos. Nessa hora o pessoal que radicaliza leva uma tremenda vantagem sobre os disciplinados como eu, que cumpro ali os segundos.

No trecho apontado, Afonso Camargo procura, também, valorizar sua própria imagem, mostrando-se como um candidato que respeita as normas do debate, o que pode torná-lo inclusive mais capacitado para assumir a presidência, uma vez que é “disciplinado”. Afirma, ainda, que esperava uma postura diferenciada de seus colegas, apontando para o público eleitor que eles não foram respeitosos como deveriam ter sido, o que coloca em destaque o fracasso dos demais candidatos em comparação com seu bom comportamento.

Observe-se a elaboração dessa estratégia no fragmento "Nessa hora o pessoal que radicaliza leva uma tremenda vantagem sobre os disciplinados como eu”. A intenção de 
Afonso Camargo nesse momento não é informar que seus adversários levaram vantagem, mas sim colocar sua imagem em destaque, legitimando o ethos do candidato que sabe seguir regras, o que é enfatizado pela expressão “como eu”. Trata-se de uma estratégia de descortesia que visa a persuadir o público eleitor, mas de maneira que a acusação seja mascarada para não prejudicar a imagem de quem a usa, uma vez que se utilizou uma expressão que não aponta diretamente para os criticados (“o pessoal que radicaliza”).

Como vimos nesta breve análise de alguns trechos do debate televisivo, há trocas verbais que se caracterizam pela presença da descortesia comunicativa, elemento que desestabiliza a interação em um certo sentido, ainda que seja, em alguns gêneros discursivos, como o debate político, elemento característico da prática discursiva. Nos trechos destacados, agressões à imagem do interlocutor (utilizando a atenuação somente com o propósito de não prejudicar a própria imagem, sem se preocupar em reparar a imagem dos demais interactantes) acompanham enunciados que procuram valorizar seu enunciador. Há, de fato, como se pode observar pela dinâmica da prática comunicativa, um jogo de implicação, em muitos gêneros discursivos, entre o cortês e o descortês, entre o privado e o público e entre a autonomia e a afiliação.

O debate político nos possibilita, como apontamos, a percepção de que a descortesia não pode ser considerada apenas como reação ou ausência de cortesia, pois muitas vezes ela auxilia a configuração do propósito essencial de determinadas interações verbais, essencialmente ancoradas na controvérsia e no conflito.

\section{Considerações finais}

Nas interações cotidianas, o que se espera é manter a harmonia para atingir sucesso, ou seja, busca-se preservar ou enaltecer as imagens tanto do enunciador quanto do coenunciador, procurando estabelecer equilíbrio. No entanto, deve-se ter em vista que nem todas as interações objetivam preservar as imagens. Há aquelas de cunho polêmico, como o debate político, no qual os candidatos têm o propósito de denegrir especialmente a imagem afiliativa de seus adversários, tendo em mira que o desejo de afiliação está relacionado também ao cumprimento do papel social de político. Nesse processo, os candidatos autopromovem a imagem que eles consideram mais oportuna para persuadir o público eleitor, conquistando votos. 
Neste trabalho, buscou-se evidenciar enunciados compostos por marcas de descortesia que serviram como estratégia discursiva na intenção de danificar a imagem do oponente no debate político em questão. Apontaram-se, então, trechos nos quais aparecem manifestações descorteses de ameaça à imagem, mas feitas de maneira a não extrapolar as regras que regem a interação (os candidatos não faltaram com educação nem partiram para agressão física, por exemplo), acusando os adversários de maneira indireta, uma vez que tem de haver o cuidado dos presidenciáveis para preservar e enaltecer a própria imagem que eles procuram criar diante do público eleitor, legitimando o ethos criado nesse contexto discursivo.

No debate político estudado, a principal estratégia de descortesia utilizada foi a autovalorização, que pode ser observada em todos os exemplos apontados, estando também presente em meio às demais estratégias. Essa estratégia minimiza a descortesia, pois, aparentemente, o candidato está somente apontando suas qualidades e trabalhando em sua imagem de afiliação (desejo de fazer parte do grupo ao qual pertence o público eleitor) e de autonomia (desejo de mostrar o que o diferencia dos demais políticos, apontando razões para merecer o voto dos eleitores). Ainda assim, outras estratégias foram agregadas a essa, para potencializar a tentativa de destruição das imagens dos adversários, como é o caso da formulação de contrastes desvantajosos e da desqualificação do outro.

Sendo assim, as estratégias de descortesia apontadas foram utilizadas para compor a fala dos interactantes como meio de legitimar os ethé que eles procuraram criar discursivamente e para enaltecer a imagem que eles buscaram construir com a finalidade de persuadir o público eleitor. Além disso, as estratégias foram aplicadas com o propósito de denegrir a imagem dos adversários, na tentativa de enfraquecer seus oponentes, objetivando conquistar votos para ganhar o pleito.

BATISTA, Ronaldo de Oliveira; ANDRADE, Mariana Santos de. Self-worth and impoliteness in election debate: an analysis of the 1989 political debate on the tv. Revista do Gel, v. 14, n. 1, p. 253-268, 2017.

Abstract: This paper analyzes the occurrence of impolite manifestations in the Brazilian presidential debate of 1989, which aimed the election of a new president in the first round. The paper was based on the studies created by Bravo (1999, 2003, 2004a, 2004b), Blas 
Arroyo (2001, 2010) and Silva (2013), following a documental analysis, in which excerpts of television videos of debates constitute the corpus. We aim to understand and analyze communication strategies used in impolite speech acts. Therefore, it will be taken into consideration that a debate is a controversial interaction, in which the goal is to damage the other's reputation at the expense of enhancing the speaker's reputation, and that can make impoliteness the rule.

Keywords: Impoliteness. Political Debate. Conversational Analysis. Pragmatics.

Submetido em: 21/06/2016.

Aceito em: 13/09/2016.

\section{Referências}

BLAS ARROYO, J. L. “No digas choradas...”. La descortesía en el debate político cara a cara. Una aproximación variacionista. Oralia, n. 4, p. 9-45, 2001.

La descortesía en contextos de telerrealidad mediática. Análisis de un corpus español. In: ORLETTI, F.; MARIOTTINI, L. (Des)cortesía en español. Espacios teóricos y metodológicos para estudio. Roma/Estocolmo: Universitá degli Studi Roma Ter - EDICE, 2010. p. 183-209.

BOLÍVAR, A. La descortesia como estrategia política en la democracia venezolana. In: BRAVO, D. (Ed.). Actas del Primer Coloquio del Programa EDICE. Estocolmo: EDICE, 2003. p. 213-226.

BRAVO, D. ¿Imagen positiva vs. imagen negativa? Pragmática social y componentes del face. Oralia, n. 2, p. 155-184, 1999.

Actividades de cortesía, imagen social y contextos socioculturales: una introducción. In: BRAVO, D. (Ed.). Actas del Primer Coloquio del Programa EDICE. Estocolmo: EDICE, 2003. p. 98-108.

. Panorámica breve acerca del marco teórico y metodológico. In: BRAVO, D.; BRIZ, A. (Ed.). Pragmática sociocultural: estudios sobre el discurso de cortesía en español. Barcelona: Editorial Ariel, S. A., 2004a. p. 5-11.

Tensión entre universalidad y relatividad en las teorias de la cortesía. In:

BRAVO, D.; BRIZ, A. (Ed.). Pragmática sociocultural: estudios sobre el discurso de cortesía em español. Barcelona: Editorial Ariel, S. A., 2004b. p. 15-37.

BROWN, P.; LEVINSON, S.C. Politeness some universals in language usage. Cambridge: Cambridge University Press, 1987. 
CULPEPER, J. Toward an anatomy of impoliteness. Journal of Pragmatics, 25 (3), p. 349-367, mar. 1996.

GOFFMAN, E. Interaction ritual: essays on face-to-face behaviour. New York: Garden City, 1967.

HERNÁNDEZ FLORES, N. La cortesía como la búsqueda del equilibrio de la imagem social. In: BRAVO, D.; BRIZ, A. (Ed.). Pragmática sociocultural: estudios sobre el discurso de cortesía en español. Barcelona: Editorial Ariel, S. A., 2004. p. 95-108.

SILVA, L. A. Descortesia e (des)construção da imagem pública. In: PRETI, D.; LEITE, M. Q. (Org.). Comunicação na fala e na escrita. São Paulo: Humanitas, 2013. p. 93119.

WEBER, M. H. Comunicação e Espetáculos da Política. Porto Alegre: Ed. Universidade/UFRGS, 2000. 